\title{
Hypersensitivity Pneumonitis: Perspective in Diagnosis and Pathology
}

\author{
Shijia Xia \\ ZJU-UOE Institute, Zhejiang University, School of Medicine, Haining, China
}

\begin{abstract}
Hypersensitivity pneumonitis (HP) is the excessive immune response in the lung parenchyma (alveoli, terminal bronchiole, interstitium), resulting from repeated exposure to a variety of antigens. From the clinical point of view, HP can be divided into acute, subacute, or chronic forms. Only few of the exposed individuals develop HP, but workers in environments contaminated by organic dust are at a higher risk. The pathogenesis of HP is complex and still under investigation. Previous research suggests that both type III and IV hypersensitivity reactions are involved. The main treatment is the removal of antigen. Therefore, research of causative agents and pathogenesis is of outstanding importance not only for early diagnosis but also the better treatment of HP.
\end{abstract}

\section{Introduction}

Hypersensitivity pneumonitis (HP), or extrinsic allergic alveolitis, is an excessive immune response in the lung parenchyma (specifically, alveoli, terminal bronchiole, interstitium), secondary to repeated exposure to antigens by susceptible individuals (Selman et al., 2012). It can be caused by multiple antigens, such as microbes, animal and plant proteins, and some chemical components. Notably, new HP antigens are being constantly reported (Selman et al., 2017). Based on the causative antigens, HP can be categorized into many subtypes (Table 1). Syndrome may vary in symptoms severity, clinical presentation and prognosis, depending on the type and intensity of exposure, and host risk factors (Selman et al., 2012). Depending on the intensity and frequency of antigen exposure, HP can be divided into acute, subacute and chronic clinical forms. In most cases, symptoms can be reversed by removing the antigens. However, chronic HP will cause constant inflammation and often evolve to irreversible lung fibrosis (Selman et al., 2012).

The prevalence of HP is difficult to determine and varies depending on exposure modalities, geographical conditions, agricultural and industrial practices, and host factors (Riario Sforza and Marinou, 2017). The one-year prevalence rates ranged from 1.67 to 2.71 per 100,000 individuals around the world (Fernández et al., 2018). Due to the lack of a standardized disease definition, diagnostic methods and criteria, underdiagnosis may probably happen (Ohshimo et al., 2012). Notably, workers in environments contaminated by organic dust are at a higher risk. The farmer's lung disease (FLD) and pigeon breeder's lung disease are the most common types of HP. It is estimated that HP affect from 1-19\% of farmers exposed to moldy hay and $6-20 \%$ of individuals exposed to bird droppings (Spagnolo et al., 2015).
The immunopathogenesis of the disease is still under investigation. Current concept is that the acute and chronic form can be best explained by the type III and type IV hypersensitivity reaction, respectively. Type III hypersensitivity reactions are mediated by immune complexes. Antigen-antibody complexes activates complement and creates an inflammatory response with neutrophilic infiltrate, which causes tissue damage. Type IV hypersensitivity reactions are mediated by Thl cells and provoked by leukocytes that infiltrate the antigen exposure site. Given the fact that only some exposed individuals develop HP, whereas others with the same exposure have no clinical consequences, the existence of a genetic predisposition to HP is suggested (Selman et al., 2012).

Though corticosteroids may help to control some symptoms, they appear to have no effect on the longterm outcome of the disease (Kokkarinen, Tukiainen, and Terho, 1992). At present, the main treatment is still the removal of antigen. Therefore, more advanced diagnostic methods are required not only allows to an early diagnosis but also a better treatment. 
Table 1. Common Types of Hypersensitivity Pneumonitis According to Major Classes of Antigens (Spagnolo et al., 2015)

\begin{tabular}{|c|c|c|c|}
\hline Class of Antigens & Specific Antigens & Sources & Type of Disease \\
\hline Bacteria & $\begin{array}{l}\text { Saccharopolyspora rectivirgula, } \\
\text { Thermoactinomyces vulgaris }\end{array}$ & Moldy hay, grain & Farmer's lung \\
\hline Fungi, yeasts & $\begin{array}{l}\text { Aspergillus species } \\
\text { Aspergillus species } \\
\text { Trichosporon cutaneum } \\
\text { Penicillium species } \\
\text { Penicillium casei } \\
\text { Alternaria } \text { species }\end{array}$ & $\begin{array}{l}\text { Moldy hay, grain } \\
\text { Moldy compost and mushrooms } \\
\text { Contaminated houses } \\
\text { Moldy cork } \\
\text { Moldy cheese or cheese casings } \\
\text { Contaminated wood pulp or dust }\end{array}$ & $\begin{array}{l}\text { Farmer's lung } \\
\text { Mushrooms worker's lung } \\
\text { Japanese summer-type HP } \\
\text { Suberosis } \\
\text { Cheese washer's lung } \\
\text { Woodworker's lung }\end{array}$ \\
\hline \multirow[t]{2}{*}{ Mycobacteria } & Mycobacterium avium-intracellulare & Mold on ceiling, tub water & Hot tub lung \\
\hline & Mycobacterium avium-intracellulare & $\begin{array}{l}\text { Mist from pool water, sprays } \\
\text { and fountains }\end{array}$ & Swimming pool lung \\
\hline \multirow[t]{3}{*}{ Animal proteins } & $\begin{array}{l}\text { Proteins in avian droppings and serum } \\
\text { and on feathers }\end{array}$ & $\begin{array}{l}\text { Parakeets, budgerigars, pigeons, } \\
\text { parrots, cockatiels, ducks }\end{array}$ & $\begin{array}{l}\text { Pigeon breeder's lung, } \\
\text { bird fancier's lung }\end{array}$ \\
\hline & Avian proteins & Feather beds, pillow, duvets & Feather duvet lung \\
\hline & Silkworm proteins & $\begin{array}{l}\text { Dust from silkworm larvae } \\
\text { and cocoons }\end{array}$ & Silk production HP \\
\hline Chemicals & Diisocyanates, trimellitic anhydride & $\begin{array}{l}\text { Polyurethane foams, spray paints, } \\
\text { dyes, glues }\end{array}$ & Chemical worker's lung \\
\hline
\end{tabular}

\section{Pathogenesis}

HP antigens are less than $5 \mu \mathrm{m}$ in diameter, which is small enough to reach the alveoli and provoke an immune response of the lung parenchyma (Riario Sforza and Marinou, 2017). Lung parenchyma, specifically the alveoli, terminal bronchiole, and interstitium, is the portion outside of the circulation system that is involved in gas exchange. Due to the requirements of gas exchange, this part is not protected by mucus and cilia. Instead, alveolar macrophages, interstitial macrophages, monocyte, lymphocyte, and dendritic cells contribute to the immune defence.

Non-suspectable individuals will develop immune tolerance to the inhaled antigens, at most a mild increase of local lymphocytes without clinical consequences. Though the mechanisms of this tolerant response are not clear, it might be mediated by regulatory $\mathrm{T}$ cells (Treg) (Selman et al., 2012). Treg cells are a type of CD4+ T cells that suppress $\mathrm{T}$-cell proliferation and play an important role in preventing excessive reactions. Previous research has suggested that mice with specific elimination of Treg cells in vivo will develop fatal autoimmune pathology. This might be explained by that Treg cells continuously suppress self-reactive $\mathrm{T}$ cells to prevent autoimmunity (Kim et al., 2006). In another study, researchers obtained Treg cells of normal unexposed individuals, asymptomatic exposed subjects and FLD patients from their blood samples and bronchoalveolar lavage (Girard, Israe"l-Assayag, and Cormier, 2011). They have found that Treg from unexposed or asymptomatic exposed subjects were able to suppress T-cell cells proliferation. However, Treg from FLD patients were totally nonfunctional and unable to suppress the proliferation of activated $\mathrm{T}$ cells. Therefore, Treg cells may be involved in antigen tolerance in non-suspectable individuals.

The acute form of HP occurs a few hours after an intense antigen exposure. Symptoms are non-specific and flu-like, including malaise, dyspnea, fever, and cough (Cano-Jiménez et al., 2016). These symptoms usually start a few hours after exposure, decrease over hours or days but will recur with repeated exposure. It has been suggested that acute HP can be explained by the type III hypersensitivity reaction (Selman et al., 2012), which is caused by the formation of immune complexes that are not well cleared by innate immune cells (Mir, 2015). This concept can be supported by the findings of activated complement components and blood neutrophils, and bronchoalveolar lavage (BAL) neutrophilia in acute HP patients (Selman et al., 2017). Antibodies (particularly IgG) produced by plasma cells precipitate and form immune complexes with the antigen. Immune complexes stimulate the alveolar macrophages to secrete various inflammatory mediators, which produce an acute inflammatory reaction, characterized by the migration of neutrophils into the lung and direct damage to bronchoalveolar epithelium (Mohr, 2004).

Subacute and chronic forms of HP occur after exposure of longer periods but lower antigen levels. Clinical presentation includes progressive dyspnea, cough, fatigue, malaise, and weight loss (Cano-Jiménez et al., 2016). The pathogenesis can be explained by type IV hypersensitivity reactions mediated by Th1 cells. Type IV hypersensitivity is provoked by leukocytes that infiltrate the antigen exposure site. A delayed form of inflammatory tissue damage will be induced (Mak, 2014). The underlining mechanisms of the T-cell alveolitis are not completely understood but appear to include increased T-cell recruitment, migration, and proliferation in the local microenvironment, and decreased programmed cell death (Selman et al., 2017). On interaction with the HP antigen presented by dendritic cells and macrophages, CD4+ $\mathrm{T}$ cells (the helper $\mathrm{T}$ cells) can be differentiated into $\mathrm{Th} 1, \mathrm{Th} 2$, and a variety of other subsets. IL-12 produced by dendritic cells and IFN $\gamma$ produced by $\mathrm{T}$ cells and natural killer cells, skew lymphocytes toward the Th1 cell differentiation program (Selman et al., 2012). Th1 cells produce cytokines that recruit macrophages and mediate tissue injury. IFN $\gamma$ activates macrophages and promotes 
Table 2. Significant Predictors of Hypersensitivity Pneumonitis (Lacasse et al., 2003).

\begin{tabular}{lccc}
\hline Variables & Coefficient & Odds Ratio & Confidence Interval \\
\hline Intercept & -6.57 & - & - \\
Exposure to a known offending antigen & 3.66 & 38.8 & $11.6-129.6$ \\
Positive precipitating antibodies & 1.68 & 5.3 & $2.7-10.4$ \\
Recurrent episodes of symptoms & 1.20 & 3.3 & $1.5-7.5$ \\
Inspiratory crackles & 1.51 & 4.5 & $1.8-11.7$ \\
Symptoms 4-8 h after exposure & 1.97 & 7.2 & $1.8-28.6$ \\
Weight loss & 0.70 & 2.0 & $1.0-3.9$ \\
\hline
\end{tabular}

the release of inflammatory mediators. TNF- $\alpha$ and TNF$\beta$ enhance vascular permeability and damage local tissue. These interactions will result in the amplification of antigen-specific $\mathrm{T}$ cells, which initiates the hypersensitivity reaction.

\section{Diagnosis}

Various conventional diagnostic criteria have been proposed for HP, but none of these has been validated. Subacute and chronic HP may mimic any interstitial lung disease, making it challenging to recognize and differentiate HP from other interstitial lung diseases (ILDs) (Vasakova et al., 2017). For example, chronic HP may be misdiagnosed as idiopathic pulmonary fibrosis (IPF). Therefore, clinicians should always consider HP in the spectrum of the differential diagnosis, including antigen exposure history, clinical features, inhalational challenge, and radiological and pathologic abnormalities (Spagnolo et al., 2015). Diagnostic steps should include a thorough evaluation of the patients' history, physical examination, antigen detection for confirmation of exposure, high-resolution computed tomography (HRCT), and BAL. A lung biopsy will be considered if the diagnosis remains uncertain. If a lung biopsy is contraindicated, specific inhalation challenge can be used to confirm the causative antigen of the disease (Vasakova et al., 2017). Table 2 shows 6 significant predictors of HP, and the probability of having HP is $98 \%$ if all these 6 criteria are met (Lacasse et al., 2003).

\subsection{Physical examination}

Physical examination usually reveals fine crackles for acute HP patient and dry crackles for chronic HP patient on pulmonary auscultation (Cano-Jiménez et al., 2016). Crackles, or rales, are the crackling noises produced in the bronchial tubes or air spaces of the lungs by the movement of air in the presence of liquid, or by the separation of moist surfaces. There are two varieties, the moist crackles due to moisture in the air vesicles and the dry crackles occurring in emphysema. The moist crackle can be further divided into coarse, medium and fine (Kinghorn, 1932). Abnormal lung function is common in most HP patients. However, these abnormalities are nonspecific for HP and revealed in most ILDs. Therefore, the importance of pulmonary function tests is to evaluate severity of lung function impairment at all time of diagnosis (Vasakova et al., 2017). HP is characterized by a restrictive functional pattern with a decreased forced vital capacity (FVC) and reduced total lung capacity (TLC). HP patients also reveal declines in forced expiratory volume (FEV1) and moderate to severe reduction of the carbon monoxide diffusing capacity (DLCO). Long-term exposure to antigens will result in an accelerated decline in pulmonary function. In acute $\mathrm{HP}$, lung function might be normal at rest, but patients may develop hypoxemia with exercise. Lung function studies in chronic HP are still needed (Selman et al., 2017).

\subsection{Antigen detection}

Serum precipitins against potential antigens can be used as a marker of exposure which can support diagnosis. Electrosyneresis and enzyme immunoassay can be used to detect HP antigens. Positive precipitating IgG antibodies to the offending antigen is evidence of exposure and sensitization but not of disease (Selman et al., 2012). Nevertheless, false-negative results might be seen in acute and chronic HP (particularly if the pathology is usual interstitial pneumonia). Since most commercial assays test a small fraction of causative antigens, the absence of serum precipitins cannot reject diagnosis of HP (Spagnolo et al., 2015).

\subsection{Radiology}

HRCT plays a central role for diagnosis. It is a useful method for separating the clinical forms of HP. In acute HP, HRCT may be normal, or show abnormal findings such as ground-glass attenuation (a diffuse and hazy increase of parenchymal density) or widespread air space consolidation (Selman et al., 2012). In subacute HP, patients show poorly defined small nodules, groundglass opacities, and mosaic attenuation. In chronic HP, patients are characterized by reticular opacities in addition to findings of subacute HP. In chronic patients that show slowly insidious disease, reticulation maybe develop into honeycombing. Honeycombing without subpleural sparing or centrilobular nodules can best distinguish IPF from chronic HP (Selman et al., 2017).

\subsection{BALF cellular analysis}

BAL may provide important support for HP diagnosis because it is highly sensitive to detect lung inflammation in patients suspected for HP. HP, in any of its clinical presentations, is characterized by an increase in the total cell count with an elevation (usually more than $30 \%$ and often over $50 \%$ ) in the percentage of $\mathrm{T}$ lymphocytes 
(Selman et al., 2017). Additional features that support the diagnosis of HP are the presence of mast cells, plasma cells, and foamy macrophages in the BAL (Spagnolo et al., 2015).

\subsection{Histopathology}

Acute HP patients rarely undergo lung biopsy because it is not necessary for diagnosis. In the few reported cases, the main characteristics were fibrin deposition and neutrophils (Spagnolo et al., 2015). Subacute HP is characterized by a granulomatous interstitial bronchiolocentric pneumonitis. The granulomas are small, nonnecrotizing, and loosely arranged (Selman et al., 2012). Chronic HP patients show interstitial fibrotic changes and architectural distortion superimposed on subacute findings. Chronic HP may have similar characteristic of other ILDs, including fibrosing nonspecific interstitial pneumonia (NSIP), airwaycentered interstitial fibrosis, and usual interstitial pneumonia (UIP). The main features for differentiating chronic HP from IPF are centrilobular fibrosis, significant lymphoid infiltrate, and small granulomas (Spagnolo et al., 2015).

\subsection{Specific inhalation challenge}

A specific inhalation challenge (SIC) test is the controlled exposure of a patient to a suspected inciting antigen under laboratory conditions. SIC conducted with suspected antigens is used to confirm the diagnosis in unclear cases (Cano-Jiménez et al., 2016). The patient should be monitored for at least 24 hours, and a positive test is characterized by cough, dyspnea, fever and decreased FVC after antigen exposure (Spagnolo et al., 2015).

\section{Treatment}

The treatment of HP is based mainly on avoidance of exposure to a suspected agent. For patients at early stage, symptoms can be reversed by removing the causative antigens. In cases in which removing antigen dose not result in full recovery, treatment with glucocorticosteroids is recommended. Corticosteroids accelerate recovery in the acute forms but appear to have no effect on the long-term outcome of the disease (CanoJiménez et al., 2016). Immunosuppressive treatments have been tested on some types of HPs such as bird fancier's lung. However, few published cases have reported improvement in those patients (Keir, Maher, and Ming, 2014). Lung transplantation is indicated in patients with respiratory failure. A study found that lung transplantation improved 5-year survival of HP patients (Kern et al., 2015).

\section{Discussion}

In summary, HP is a complex disease, and its pathogenesis is not fully understood. Though the prevalence of HP is quite low, this disease may be underdiagnosed due to its insidious onset, nonspecific syndrome and lack of standard diagnostic criteria. Symptoms can be reversed by removing causative antigens at early stage, in chronic HP patients, however, antigen avoidance may not reverse the disease. Chronic HP will cause constant inflammation and often develop into irreversible lung fibrosis. Previous research suggests that genetic susceptibility and environmental factors are potential risk factors of HP. It has been reported that the high level of polymorphism and heterozygosity within the major histocompatibility complex (MHC) region has added the risk of generating diverse immunopathological disorders. MHC class II molecules appear to be the susceptible locus in HP (Selman et al., 2012). However, much confusion still surrounds the pathogenesis of HP. The mechanisms by which MHC polymorphism is associated with HP remain unclear. As for the treatment, since removal of antigen is still the main treatment, early diagnosis and avoidance of antigen exposure are key actions in the management of HP. Further research is needed to improve the early diagnosis and understanding of the pathogenesis of HP, and therefore, drive clinical decision making.

\section{Acknowledgement}

I would like to express my gratitude to all those who helped me during the writing of this review. First and foremost, my sincere appreciation goes to my supervisor who has provided me with valuable guidance in every stage of the writing. I would also like to thank all my teachers who have helped me to develop the fundamental and essential academic competence. Last but not least, I' $\mathrm{d}$ like to thank all my parents and friends for their encouragement and support.

\section{References}

1. CANO-JIMÉNEZ, E., ACUÑA, A., BOTANA, M., HERMIDA, T., GONZÁLEZ, M., LEIRO, V., MARTÍN, I., PAREDES, S. \& SANJUÁN, P. (2016). Farmer's Lung Disease. A Review. Archivos de Bronconeumología, 52(6), pp.321-328.

2. FERNÁNDEZ PÉREZ, E., KONG, A., RAIMUNDO, K., KOELSCH, T., KULKARNI, R. \& COLE, A. (2018). Epidemiology of Hypersensitivity Pneumonitis among an Insured Population in the United States: A Claims-based Cohort Analysis. Annals of the American Thoracic Society, 15(4), pp.460-469.

3. GIRARD, M., ISRAEL-ASSAYAG, E. \& CORMIER, Y. (2010). Impaired function of regulatory T-cells in hypersensitivity pneumonitis. European Respiratory Journal, 37(3), pp.632-639.

4. KEIR, G., MAHER, T., MING, D., ABDULLAH, R., DE LAURETIS, A., WICKREMASINGHE, M., NICHOLSON, A., HANSELL, D., WELLS, A. \& RENZONI, E. (2013). Rituximab in severe, 
treatment-refractory interstitial lung disease. Respirology, 19(3), pp.353-359.

5. KERN, R., SINGER, J., KOTH, L., MOONEY, J., GOLDEN, J., HAYS, S., GREENLAND, J., WOLTERS, P., GHIO, E., JONES, K., LEARD, L., KUKREJA, J. AND BLANC, P. (2015). Lung Transplantation for Hypersensitivity Pneumonitis. Chest, 147(6), pp.1558-1565.

6. Kinghorn HM. THE CLASSIFICATION OF RALES. Can Med Assoc J. 1932;26(4):438-445.

7. KOKKARINEN, J., TUKIAINEN, H. \& TERHO, E. (1992). Effect of Corticosteroid Treatment on the Recovery of Pulmonary Function in Farmer's Lung. American Review of Respiratory Disease, 145(1), pp.3-5.

8. Lacasse Y, Selman M, Costabel U, Dalphin JC, Ando M, Morell F, Erkinjuntti-Pekkanen R, Muller N, Colby TV, Schuyler M, Cormier Y; HP Study Group. Clinical diagnosis of hypersensitivity pneumonitis. Am J Respir.Crit Care Med. 2003;168:952-8

9. Mak, T. (2014). Primer to the Immune Response. 2nd ed. Boston: Academic Cell, pp.487 - 516.

10. MIR, M. (2015). Developing costimulatory molecules for immunotherapy of diseases. Academic Press, pp.131-184.

11. MOHR, L. (2004). Hypersensitivity pneumonitis. Current Opinion in Pulmonary Medicine, 10(5), pp.401-411.
12. Ohshimo S, Bonella F, Guzman J, Costabel U. Hypersensitivity Pneumonitis. Immunol Allergy Clin N Am. 2012. 32:537-556

13. Riario Sforza and Marinou Clin Mol Allergy (2017) 15:6 DOI 10.1186/s12948-017-0062-7

14. SELMAN, M., PARDO, A. \& KING, T. (2012). Hypersensitivity Pneumonitis. American Journal of Respiratory and Critical Care Medicine, 186(4), pp.314-324.

15. SELMAN M., BUENDÍA-ROLDÁN I., NAVARRO C., GAXIOLA M. (2017) Hypersensitivity Pneumonitis. In: Baughman R., Carbone R., Nathan S. (eds) Pulmonary Hypertension and Interstitial Lung Disease. Springer, Cham

16. SPAGNOLO P., ROSSI G., CAVAZZA A., BONIFAZI M., PALADINI I., BONELLA F., SVERZELLATI N., \& COSTABEL U. (2015) Hypersensitivity Pneumonitis: A Comprehensive Review. Journal of Investigational Allergology and Clinical Immunology, 25 (4), pp. 237-250.

17. Vasakova, M., Morell, F., Walsh, S., Leslie, K. and Raghu, G. (2017). Hypersensitivity Pneumonitis: Perspectives in Diagnosis and Management. American Journal of Respiratory and Critical Care Medicine, 196(6), pp.680-689. 